\title{
Reorientation and Renewal of Indonesia Economy Education Curriculum Paradigm based on Creative Economy, Character Education and Local Cultural Values
}

\author{
Moch Noviadi Nugroho \\ Universitas Pendidikan Indonesia \\ Bandung, Indonesia \\ adienugroho@student.upi.edu
}

\begin{abstract}
The shift of development paradigm, which initially rests on the power of natural resources based, then changed to rely on the strength of human resources based or commonly also called knowledge-based economy. Creative economy is an economic era that intensifies information and creativity by relying on the idea. The economic strength is now mandatorybased creativity, innovation-based ideas and imagine. Knowledge based economy or the creative economy, Indonesia needs to develop creative economy among other things because of the creative economy has great potential to contribute significant economic, image building and national identity, develop based economy to a renewable resource, providing a positive socioeconomic impacts. One reason for the development of creative industries is the positive effect that will affect the social life, business climate, economic improvement, and also affects the image of a nation. Indonesia is an archipelago large, consisting of 17,504 islands with the diversity and cultural richness. There are 1,068 ethnic groups and 665 languages to communicate with regions across the archipelago. In the field of art and culture there are at least $\mathbf{3 0 0}$ styles of traditional dance originating from Sabang to Merauke. Richness of Indonesian culture is great potential in supporting the growth of Indonesia's creative industries. The modalities and the strength of the nation Indonesia, which has a creative human resources and cultural heritage (culture heritage) are very diverse. College of Education curriculum designing creative-oriented economy and entrepreneurship (entrepreneurship) and synergize utilizing ICT (information and communication technology) in its development. Economic Education can be integrated from a variety of disciplines, Economic Education can not escape from the education requirement value (value-based education) and thick with the paradigm of development of human life as its main object, which should be dynamic, flexible and adaptive. The development of education are more advanced and complex challenges for Economic Education to strengthen the tradition of synthetical Science, Expanding Environment Approach in public life more advanced and globalized, so it is not only seen as creative content, but also can be implemented in everyday life, as a science that is able to overcome the challenges faced. Economic Education as an educational requirement value. The gap between the quality of education for Economic Education in empirical reality with the ideal demands. The relevance of the curriculum with the practical life and development of society constantly demands to do educational innovation. It needs a redesign,
\end{abstract}

reorientation, re-actualization education Economic Education, reaffirmed the vision of education for Economic Education as an educational program that focuses on the development of students as "economic actors" who is able to take decisions that reason and as "citizens who are intelligent, committed, responsible, and participatory ". Reaffirming Economic educational mission to utilize the concepts, principles and methods of the social sciences and other disciplines to develop a character actor of economic and social change and the citizens of Indonesia are intelligent and good. Re-establish the tradition of economic education as an educational requirement of social values, morals, culture, and character. Economic Education curriculum development approach emphasizes the material (content-based approach), the basic approach is the ability (competence based approach), the approach of basic skills (basic skills approach). Economic Education Curriculum development should be based on the principle centered on the needs of learners competence of hard skills and soft skills, learner needs, interests of learners and the environment. Diverse and integrated, responsive to the development of science, technology and art, relevant to the needs of life, comprehensive and sustainable, through a multi strategy and multi-media. Economic Education Curriculum design is centered on the learner include: (1) design based on experience / activity (activity / experience design); and (2) the design of humanistic (humanistic design). Economic Education Curriculum Design humanistic aims to equip learners with experiences that are intrinsically beneficial to the development of self-learning, among other things, strengthening self-concept. PAI curriculum centered on Problems (Problem-Centered Designs), centered on the issue of direct learners to the ability to solve problems faced by both life itself and its people. The idea of the Economic Education Curriculum, Competency-based curriculum, based on standards-based, rooted in the culture, emphasizing a balance between Soft Skills and hard skills. Developmental content, developed through a continuous learning activities and sustainable. various approaches to curriculum development through academic subject approach, humanistic approach, technological approach, economic and reconstruction approach Mental Rekrontruction and social-oriented approach on Purpose, subject matter, Correlated Curriculum, Integrated Curriculum approach. 
Keywords- Economic Education Curriculum Approach Cultural Values Character, Academic Approach Humanistic and Economic and Social Reconstruction

\section{INTRODUCTION}

The influence of globalization has reduced the values of national culture. The local culture has the potential and role as counterculture (counter culture) for dominance of global culture mythologized as something inevitable. Kasanah local culture can be a source of local wisdom, as one source of critical attitude to globalization. Elements of culture and local wisdom as a basis for curriculum development to provide reinforcement to the local cultural symbol. develop a curriculum that is sourced to based culture and local wisdom. as an effort to revitalize the values, philosophy or worldview; system in the public life interact. natural and cultural wealth owned. Indonesia needs to be protected as well as the need of conservation efforts. redefined the conscious transformation of humanist education, dialogical, critical, reflective and ecological. enable a balanced physical (hand on), feeling (feelon), and mind (mind on). competencies integral in three forms, namely: knowledge (knowledge), attitude (attitude), and skills (skills). Acceleration of the implementation of national development priorities do with curriculum improvement and active learning methods based on cultural values form the nation's competitiveness and national character. The renewal aspect united in the spirit and mission for reform of learning (school reform), and even education reform (education reform). Reform in Education involves aspects of a broader, such as institutional reform, regulation / legilasi, management, finance, and human resources. All of this can only be done with a foundation of political commitment (political will) to advance the state of education. The gap between the quality of education for Economic Education in empirical reality with the ideal demands. The relevance of the curriculum with the practical life and development of society constantly demands to do educational innovation. It needs a redesign, reorientation, education renewal of Economic Education. Economic Education curriculum development approach emphasizes the material (content-based approach), the basic approach is the ability (competence based approach), the approach of basic skills (basic skills approach). Economic Education Curriculum development should be based on the principle centered on the needs of learners competence of hard skills and soft skills, learner needs, interests of learners and the environment. Diverse and integrated, responsive to the development of science, technology and art, relevant to the needs of life, comprehensive and sustainable, through a multi strategy and multi-media. Economic Education Curriculum design is centered on the learner include: (1) design based on experience / activity (activity / experience design); and (2) the design of humanistic (humanistic design).

\section{LITERATURE REVIEW}

The concept of the creative economy is an economic concept in the new economic era that intensifies information and creativity by relying on the ideas and stock of knowledge of Human Resources (HR) as the main production factor in their economic activities. The structure of the world economy undergoes a transformation rapidly along with economic growth. Economic growth was based Natural Resources (SDA) is now a human-based, from the agricultural era to the industrial age and the information. Alvin Toffler (1980) in his theory on distribution of economic civilization wave into three waves. The first wave is the wave of the agricultural economy, the second wave of industrial economy, the third. economic tide information. Some economists predict further that the fourth wave is a wave of creative economy is oriented to the ideas and creative ideas. Creative economy is highly dependent on human capital (human capital or intellectual capital, there is also a call creative capital). Creative economy requires creative human resources of course, able to generate a variety of ideas and translate them into the form of goods and services of economic value. The production process may follow the rules of the industrial economy, but the original idea was kreativitas.John Howkins (2001) defines the creative economy as an economy that makes creativity, culture, heritage, and the environment as the foundation of the future. The concept of the creative economy was then developed by economist Richard Florida (2001) of the United States. In the book The Rise of the Creative Class and Cities and the Creative Class, Florida review of creative industries in the community. Directions creative economic development is more focused on industry-based: (1) the field of creative endeavor and culture (creative and cultural industry); (2) the undertaking of creative (creative industry), or (3) Intellectual property rights such as copyright (copyright industry)(1).

Character is one's personality are formed from the internalisation of the various policies (virtues) who believed and used as a basis for perspective, think, behave, think and act. Virtue consists of a number of values, morals, norms and beliefs that are used in human life and generate social systems, economic systems, belief systems, knowledge systems, technology, and art. Character is "Moral Excellence" or moral development built on various virtues (virtues) which in turn character values that prevail in the nation's culture. Understanding the character according to the Center for Language is "innate, heart, soul, personality, character, behavior, personality, character, character, temperament, character". The character is personality, behavior, character, temper, and character ". character refers to the set of attitudes (attitudes), behavioral (behaviors), motivation (motivations), and skills (skills). Economic Education Curriculum Design humanistic aims to equip learners with experiences that are intrinsically beneficial to the development of self-learning, among other things, strengthening self-concept. The curriculum is centered on Problems (Problem-Centered Designs), centered on the issue of direct learners to the ability to solve problems faced by both life itself and its people.

The idea of the Economic Education Curriculum, Competency-based curriculum, based on standards-based, rooted in the culture, emphasizing a balance between Soft Skills and hard skills. Developmental content, developed through a continuous learning activities and sustainable. various approaches to curriculum development through academic subject approach, humanistic approach, technological approach, economic and reconstruction 
approach Rekrontruksi mental and social-oriented approach on Purpose, Approach to Pattern Material Organization (Subject Matter Curriculum, Correlated Curriculum, Integrated Curriculum). Economic Education curriculum should be based on the achievements of graduates' competence (outcomes based curriculum) that directs all graduates to achieve a certain competence. Competence future that must be possessed by students include: 1) the ability to communicate, 2) the ability to think clearly and critically, 3) the ability to solve problems by moral considerations, 4) ability to become citizens effective, 5) the ability to try to understand and tolerant of different views, 6) the ability to live in a globalized society, 7) has a broad interest in respect of life, 8) has the readiness to work, 9) have the intelligence according to their talents / interests. Life skills education to orient students to have the ability and the capital base to be able to live independently and survive in their environment. Life skills education is necessary and urgent to be applied in Indonesia because the curriculum in Indonesia tend to strengthen the ability of theoretical-academic (academic skills). Learning life skills is one of the alternatives in an effort to prepare learners to have attitude and life skills as a preparation for later life through an active learning activities, kreatis and fun. institutions education providers feel obliged to participate equip graduates with life skills (life skills) integrative, combining the potential of generic and specific, in order to solve and cope with life's problems. Life skills that should be owned by every graduate that will plunge into the community, among others, skills self-knowledge (personal skills), skills of rational thinking (thinking skills), skills social (social skills), academic skills (academic skills) and skills vocational (vocational skills). Personal skills (personal skills) which includes the skill to know oneself (self awareness)(2).

Expected model for character education should be integrate in economic curriculum. Some character education integrate in Economic Curricullum standards used to direct education are as follows; 1 . Promoting the values of ethic as the foundation of character education. 2.Identifying character comprehensively, this covers idea, feeling, and action. 3 . Using practice and effective approach to cultivate and build character. 4. Creating caring education environment. 5. Giving chances to students to express their ideas and behave. 6 . Developing appropriate curriculum which support character education. 7. Cultivating students' motivation. 8. Sharing the responsibility to all members of schools for the sake of education character. 9. Building good leadership in character education. 10. Building cooperation and good relationship with family and people around the schools. 11. Evaluating the school character, academics. The success of education character can be influenced by the technique or approach used in the teaching and learning process. Suparno, Paul, Moerti, Titisari, and Kartono (2002: 42-44), there are four models of teaching and learning in character education. There are as follows: 1. Monolithic Model, in this model, character education is considered to be a special subject. So, character education subject is treated like other subjects. This means that the teacher of character education should develop curriculum, syllabus, lesson plan and teaching Medias to teach character education subject to students. The good point of this model is that the concept of character education is delivered to students clearly. However, this means that the value learned by students is dependent on the curriculum design which means artificial. In other words it does not really give chance to students to internalize the value of character education. 2 . Integrated Model In this model, educating character values to students is the responsibility of every teacher (Washington, Clark, and Dixon 2008). In this model, the teachers can choose some character values to be inserted in their subject. By this model, it is expected that students will internalize character values habitually during their learning time. 4. Out of School Time Model, Character education can also be done out of school hours. This usually focuses more on some activities out of school and then followed by discussion after the activities. This leads students to have a real experience in practicing some character values but since it is out of school time means that this is not part of the curriculum. Thus, it is considered to be less effective to cultivate character values to students within the limitation of time. 5. Integrating Model, integrates the integrated and out of school time model. This can be done through cooperation between teachers and some other people out of schools. This model leads to a shared and cooperative activity among schools academics and people around the schools. In addition, the students will be overwhelmed by character education at school and then practice it out of school. From those four models, the most ideal and perfect model is the integrative one. This means that character education is integrated in all subjects at school and then the students get the real experience to practice character education.(3)

Character education is directed towards developing the fundamental values that became a citizen's personality. According to T. Ramli (2003), the essence and character education has the same meaning as moral education and moral education. The goal is to establish a personal Child, so that a good human being, community residents, and a good citizen. The criteria for good men, good citizens, and good citizens for a community or nation, in general are certain social values, which are influenced by the culture of the community and nation. Therefore, the essence of character education in the context of education in Indonesia is pedidikan value, namely education noble values sourced from Indonesian culture itself, in order to nurture the younger generation's personality. Character education rests on the basic character of man, that comes from universal moral values (absolute), which comes from religion is also referred to as the golden rule. Character education can have a definite purpose, if it rests on the values of the base character. Declaration ASPEN (in Brooks, 2001) suggested the existence of values that need to be assessed and used as a barometer as well as a focus character education there are 6 grades ethik main (core ethical value) which includes: (1) reliable (trustworthy) include the nature of honesty (honesty) and integrity (integrity), (2) can treat others with respect (treats people with respect), (3) responsible (responsible), (4) fair (fair), (5) affection (caring), and (6) the good citizens (good citizen).(4) The six pillars of character, translated into many character values (indicators) that need to be taught to children. Correspondingly, the values of ethics developed by the Josephson Institute of Ethics (2005: 7-12) terjabar in the book Making Ethical Decisions, explains the six pillars of character: (1) trustworthiness, (2) respect, (3) 
responsibility, (4) fairness, (5) caring, and (6) citizenship. Furthermore, Barbara A. Lewis (2004) in his book Character Building for Children express their pillars of character terjabar 10 to 56 indicators of value. Ten pillars are: (1) matter, (2) be aware of the community life, (3) cooperating, (4) fair, (5) be willing to forgive, (6) honest, (7) maintain the relationship, (8) respect for others, (9) is responsible, and (10) give priority to safety. Very similar to what Linda stated above, Diane Tillman (2004: xvi) describes in his book Living Value activities for Children Ages 3-7, on the 11 pillars of character consisting of: (1) peace, (2) the award, ( 3) love, (4) responsibility, (5) happiness, (6) cooperation, (7) honesty, (8) humility, (9) tolerance, (10) simplicity, and (11) unity. The pillars are then elaborated on ways to teach each of the pillars serve targeted to children. Without showing any difference in principle Megawangi summarizes the various theories and poured in nine pillars of character include: (1) Love God with all creation (love God, trust, Reverence, loyalty), (2) independence and responsibility (Responsibility, excellence, self reliance, dicipline, orderliness), (3) honesty, trustworthy and wise (trustworthiness, reliability and honesty), (4) respectful and courteous (respect, courtesy, obedience), (5) a generous helpfulness and cooperation (love compassion, caring empathy, generousity, moderation, cooperation), (6). confident creative and hardworking (confidence, assertiveness, creativity, resourcefullness, courage, determination, and enthusiasm), (7) leadership and justice (justice, fairness, mercy, leadership, (8) a good and humble (kindness, friendliness, humility, modesty), and (9) of tolerance, peace and unity (tolerance, flexibility, peacefullness, unity. Related to character education and the formation of noble character, the Government has also responded positively with the implementation of the National Policy of National Character Development, which contains about policy direction, the basic framework, stages and strategies used in the construction of the nation's character. Policies related to the development strategy of national character through education, has been followed up by the Ministry of Education with the various guidelines and training materials on reinforcement learning method based on cultural values to shape and character of the nation's competitiveness. Character education is developed through education will cover the knowledge, attitudes and behaviors associated with the moral values (moral knowing, moral feeling, and moral doing). Values that need to be developed through formal education at the campus consists of 18 ie (1) religious, (2) honest, (3) tolerance, (4) discipline, (5) hard work, (6) a creative, (7) mandiiri, ( 8) democratic, (9) curiosity, (10) the national spirit (11) love of the homeland, (12) the achievements, (13) friends, (14) love peace, (15) likes to read, (16) care environment, (17) social care, and (18) of responsibility. Mapping the values of good and bad and right and wrong, are classified into five, namely (1) the values associated with man's relationship with God Almighty, (2) the values associated with a culture of self, (3) values the value of the relationship with others, and (4) national values, and (5) the values related to the environment (MONE, 2010: 148). Curriculum adjustments to the demands of life, character education model like this one, have also been conducted in Taman Siswa by Ki Hajar Dewantoro pioneered the moral education method, known as "ngreti-ngroso-nglakoni", which means; know, comes to realize and mangamal-kan values believed. By integrating implementation, methods of teaching manners to the method in Islam ie "shari'ah, nature, congregations and ma'rifat. Universities are organizing character education is expected to help graduates have three types of abilities: the ability of personal, academic ability and professional capabilities. Lecturers as educators is to educate and mature and also must act as a role model figure (role model).

\section{- Upgrades Personal (Personnel Competence)}

is a must-have capability mahamahasiswa by showing the attitude, behavior and actions that reflect the personality of Indonesia, sensitivity to various problems faced by the people of Indonesia.

\section{- Upgrades Academic (Academic Competence)}

is the ability to communicate scientifically whether oral or written, control analysis equipment, as well as logical thinking, critical, systematic, analytical, have the conceptual ability to identify and formulate problems, and to be able to offer alternative solutions.

\section{- Upgrades Professional (Professional Competence)}

is the ability in the field of professional expertise is concerned, the experts are expected to have high knowledge and skills in the fields of profession.

- Enhancing the ability of critical thinking (Critical Thinking), reflective thinking (Reflective Thinking) and HOTS (High Order Thinking Skills)

by Stice, critical thinking at the core of "The what is important, but we should pay attention to the hows and whys" (Stice, 1987: 95). To answer the question of what, how, and why Allowing myself to think analytically, mahamahami, have great ideas, willing to work hard, excited to move forward, and can remember well.

- Enhancing the ability of creative thinking (creative thinking)

individual skills in using his thinking process to generate a new idea, konsruktif good based on the concepts of rational individual perception and intuition. Creative thinking involves ratios and intuition with rational thinking and imaginative ways to develop patterns and principles of a new, creative and productive thinking in solving problems. (Zuchdi, 2008: 125)

Economic Education Curriculum must be Sensitivity to social problems, ability to sensitivity that there is something of a problem arising out of or ability to judge something that big of a complex into problems simpler and separating facts that are not true so that they can get to know the real problem , Familiarize and developing 9 Character Pillars are:

- Love God and all creation (God's love, trust, Reverence, loyalty)

- Responsibility, Discipline and Self-Reliance (responsibility, excellence, self reliance, discipline, orderliness) 
- Honesty / Reliability, and Arif (trustworthines, honesty, and tactful)

- Respect and Courtesy (respect, courtesy, obedience)

- Generous, Like to help and Mutual assistance / cooperation (love, compassion, caring, empathy, generousity, moderation, cooperation)

- Confidence, Creative and Hardworking (confidence, assertiveness, creativity, resourcefulness, courage, determination, enthusiasm)

- Leadership and Justice (justice, fairness, mercy, leadership)

- Good and Humble (kindness, friendliness, humility, modesty)

- Tolerance, Peace and Unity (tolerance, flexibility, peacefulness, unity)(3)

For the community of life skills (life skills) can increase the life of the advanced and civil with indicators of the presence of: an increase in social welfare, reduction of destructive behaviors that can reduce social problems and the development of society in harmony able to integrate religious values, theory social solidarity, economic. Some type of education that needs to be given skills to prepare students to be able to have the ability to:

- Personal Skills Education is education in skills that should be given to the students in order to develop a better ability to dialogue with yourself to actualize his identity as a man who became caliph or the representative of the Creator on the planet earth.

- Social Skills Education is education in skills that should be given to the students in order to develop the ability to talk and get along well with fellow humans.

- Environmental Skills Education is education in skills that should be given to the students in order to develop the ability to dialogue as well with the natural environment surrounding, to enjoy its beauty and protect it from damage because of his actions themselves or by other humans, as well as the ability to protect themselves from its effects.

- Vocational Education or Occupational Skills' is a skill education, which needs to be given to the students in order to develop the ability to master and please type.

- Hard skills are the mastery of science, technology, and technical skills related to the field of science. Meanwhile,

- Soft skills are skills a person in touch with other people (interpersonal skills) and self-regulation skills (interpersonal skills) that are able to develop to the maximum performance. Intrapersonal skills is the skill to "regulate" themselves. Intrapersonal skills should be addressed first before one starts dealing with others.

- Life skill refers to a wide range of capabilities required to lead a life full of success and happiness, such as the ability to communicate effectively, ability to cooperate, to be a citizen who is responsible, have the skills to work, it has character, and ways to think analytically and logically, abilities, skills to express, preserve, maintain and develop themselves, feelings, attitudes, values, aspects of intellectual, social, and affective(5)

According to Geertz, Local knowledge is a way of life and science as well as various life strategies that intangible activities undertaken by local communities in addressing the various problems in the fulfillment of their needs. In a foreign language is often conceived as a local policy of "local wisdom" or local knowledge "local knowledge" or local intelligence "local genious". Local knowledge is a truth that has been a tradition, or steady in an area. Local knowledge has high value content and decent life continue to be explored, developed, as well preserved as the antithesis or socio-cultural changes and modernitasi. can be categorized in two aspects, yes it is: (a) ideas, thoughts, mind abstract; and (b) local wisdom in the form of concrete things, can be seen. The wisdom of local categories (a) covers a wide range of knowledge and vision, values and practice of the practice of a community-both derived from the previous generation of the community and which is obtained by the community in the present, that does not come from a generation before, but the variety of experiences in the present, as well as from contact with people or other cultures.(6)

The wisdom of local category (b) is usually in the form of objects artifacts, which adorn human alive, and meaningful symbol. Suardiman (Wagiran, 2010) revealed that local knowledge is identical to human behavior berhubungaan with: (1) God, (2) the signs of nature, (3) environmental / agriculture, (4) to build homes, (5) education, (6) the marriage ceremony and birth, (7) food, (8) the cycle of human life and character, (9) health, (10) natural disasters. The scope of local knowledge can also be divided into eight, namely: (1) local norms were developed, such as the 'behavior of Java', long arms and liabilities; (2) the rituals and traditions of society and the meaning disebaliknya; (3) folk songs, legends, myths and folk ritera CE- usually contains a lesson or certain messages are only recognized by local communities; (4) information and data gathered in the knowledge that most self community elders, elders, spiritual leaders; (5) The manuscript or scriptures are believed by the public; (6) the ways local community to meet his or her life daily; (7) the tool-materials used for certain requirements; and (8) the condition of natural resources / environment is commonly used da- lam daily livelihood of the people. In the sphere of culture, the physical dimensions of local knowledge covering aspects: (1) traditional ceremonies, (2) cultural heritage, (3) natural tourism, (4) the traditional transport, (5) the game of traditional, (6) the cultural infrastructure, (7) custom clothing, (8) the cultural heritage, (9) museum, (10) a cultural institution, (11) art, (12) a cultural village, (13) the arts and handycraft, (14) folklore, ( 15) dolanan children, and (16) puppets. Another source of local knowledge can be a circle that includes Javanese life: tingkeban ceremony, ceremonies of birth, circumcision, marriage, and death. Various forms of local knowledge which is the carrying capacity for the implementation and development of education in society, 
among others, local wisdom in the form of written rules about the obligation of learning, such as the obligation to follow the learning activities for residents masya rakat who are still illiterate. Local wisdom in maintaining harmonious relations amongst people, through mutual cooperation activities, local wisdom is a phenomenon which is extensive and comprehensive. Coverage of local wisdom quite numerous and diverse that it is difficult constrained by space. Traditional knowledge and wisdom is now different from local wisdom. Local knowledge is more emphasis on the place and locality of this wisdom so as not to be a wisdom that has been passed down from generation to generation. Local knowledge can be a wisdom that has recently appeared in a community as a result of natural denganlingkungan interactions and interactions with the community and other cultures. Therefore, local wisdom is not always traditional in nature because he could encompass the wisdom of the present and therefore also a wider meaning than the traditional wisdom.(7)

Increasing competitiveness of human resources were still faced with a large number of labor force, the number of unemployed (underemployed or temporarily not working), the low culture of excellence, education, poverty, government commitment, government administration, the segmentation of educational services that are less fair and knowledgeable, have values and skilled, will depend heavily on the quality of its education and training. new jobs and foster personal stance on each student to become job creators rather than job seekers so as to be able to create new products that are innovative, highvalue efficiency and no less in competing with other countries. new jobs and foster personal stance on each student to become job creators rather than job seekers so as to be able to create new products that are innovative, high-value efficiency and no less in competing with other countries. functioning national develop skills and character development and civilization of the nation's dignity. Actuality educational function allows the development of students' potentials to become a man of faith and fear of God Almighty, noble, healthy, knowledgeable, skilled, creative, independent, and become citizens of a democratic and accountable. who is able to bring humans educated, skilled and unskilled. character thinks that promotes reason and scientific truth (intellectus quaerns fidem) on the one hand, with the characters think that using religious belief (fides quaerns intellectum) on the other.(8)

Reorientation of the educational curriculum economy aims to improve the ways of learning in school or out of school so that children students more intelligent, creative, critical, and prudent in thinking and acting better than boys ever produced by conventional schools. With this reform, the students are expected to be able to recognize themselves, their personal character and grow independently (self concept), and developing his intellectual abilities in the present context is a dynamic and progressive, so that they can survive, even leading in the competition. Both aspects are united in the spirit of renewal and a mission to reform learning (school reform), and even education reform (education reform). The curriculum design based on the international community, need to be built on the foundation of multiculturalism. This is reflected in perspective and outlines the interpretation given by the internationalization strategy. Implications preparation of curriculum design includes curriculum development, teaching strategies and assessment processes and leads to an understanding of the intersection from the perspective of local, national and global and contrast the value of the system. Economic curriculum can contribute to the environment and work ethic in cross-cultural and perspectives.(9)

Economic Education Curriculum-based outcomes (outcomes based curriculum) that directs all graduates to achieve a certain competence. Competence future that must be possessed by students include: 1) the ability to communicate, 2) the ability to think clearly and critically, 3) the ability to solve problems by moral considerations, 4) ability to become citizens effective, 5) the ability to try to understand and tolerant of different views, 6) the ability to live in a globalized society, 7) has a broad interest in respect of life, 8) has the readiness to work, 9) have the intelligence according to their talents / interests. Current and the next five years, a person who successfully enter the world of work should at least have the skills / skill the following: 1) critical thinking, 2) acquisition of information technology (IT), 3) collaboration, 4) innovation, 5) health and wellness , 6) personal financial responsibility, 7) diversity, 8) entrepreneurial skills, 9) understanding of economic issues in the global economy.(10)

"Internationalisation of curriculum encompasses curriculum development, teaching strategies and assessment processes and leads to an understanding of the intersections of local, national and global perspectives and contrasting value systems. The university curriculum can Contribute an environment and ethos where cross-cultural capabilities and global perspectives are valued and respected and its graduates are Tus equipped to live and work in the global arena ". Pedagogic practices of this kind are influenced by a theoretical and conceptual underpinning of Assumptions and prejudices held about the 'others' rather than by the pedagogic requirements of a diverse learning context. To recognise that diverse learning context, practitioners need to be reflexive and Be Able to critically question Reviews their own teaching and learning orientations as well as the cultural orientations that shape Reviews their teaching to make sense of Reviews their practices. The curriculum was developed using the philosophy as follows: (a). Education is rooted in the nation's cultural life of the nation to build the present and the future. (B). Learners are the inheritors of the nation's cultural creative. (C) Education aimed at developing the intellectual and academic excellence through education disciplines. (D). Education to build the life of the present and the future better than the past with different intellectual abilities, communication skills, social attitudes, awareness, and participate to build community life and a better nation (experimentalism and social reconstructivism). The curriculum was developed on educational theory based on the standard "(standard-based education), and the theory of competency-based curriculum.(11)

As for creative thinking, the author Roger von Oech believes that this involves imagining the familiar things in a new light, digging deep in order to find both previously undetected patterns, and connections between unrelated phenomena. From all these definitions, it is clear that they share the view that creativity is something: new, innovative, 
original, and unique. "Traditional" teacher-centred and teacher-directed forms of teaching still dominate in our universities and as argue Montuori (in Bocchi et al., 2014, p. 338) „educational systems are designed to develop conformity, black-and- white thinking, and a preference for simple answers" in contrast to creativity that requires independence of judgment, tolerance of ambiguity and a preference for complexity. In this regard, Larry Livingston (2010) points out that traditional pedagogies and courses of study leave little or no room for new experiences. According Hossieni (2011) traditional methods of teaching „emphasize direct transmission of knowledge and maintain these processes through inflexible structures which limit the engagement of learners in innovation, discovery and mental growth. Problemsolving and inquiry oriented approaches on the other hand, offer opportunities for exploring and discovering complexities, involving learners with the process of learning, and enhancing internal motivation." Creative learning and teaching include, establish and maintain those processes (Hossieni, 2011). In order to foster creativity the learning processes "must develop self-efficacy, encourage risk taking in safe environments and help students to engage with mess/complex and unpredictable situations where there are no right and wrong answer" (Sadeghi \& Ofoghi, 2011, p. 264). Hossieni and Khalili (2011, p. 1311) argue that "educational curriculum and content should be on the base of problem-solving" and flexible, variable and plural (postmodern) curriculum related with factual problems in life can be the opportunity for creativity and innovation. Ronald A. Beghetto and James C. Kaufman (2013) stated that ,creativity has become a hot topic in education" and there are many voices (media, government officials, education policymakers etc.) calling for including student creativity in the curriculum. To achieve this goal is essential clear understanding of the nature of creativity itself. Authors present five fundamental insights that can help/guide educators in their endeavour to integrate student creativity into the everyday curriculum: (1) creativity takes more than originality: creativity combines both originality and task appropriateness and those teachers and educators who understand this are in a better position to integrate student creativity into the everyday curriculum; (2) there are different levels of creativity: some instances of creativity occur every day, other instances of creativity redefine the way things are done or even transform history; (3) context matters: certain contexts can curtail and suppress creativity; (4) creativity comes at a cost: part of encouraging creativity includes helping students become aware of the potential costs and benefits associated with creative expression - it will help them to determine whether the risk is worth it; (5) there's a time and a place for creativity: accomplished creators know when to be creative that is why teachers/lecturers need to teach how to read a situation and determine whether and how to express one's creative ideas, insights, and behaviours(8).

To enhance the quality of teaching and learning process experiential, non-traditional and innovative strategies should be utilized. In education, as in other areas, it is possible to apply Rohnke's (also known as Tuson's) model of comfort stretch/learning - panic zones. Using traditional (classical) teaching methods keep students in comfort zone for which is typical that a person work only on the basis of previous experience and knowledge, use skills and solve tasks that has mastered, has no need or motivation to change anything. Getting students out from comfort zone into the stretch (learning) zone is not very comfortable, but it is stimulating. In this zone students do/try "new" things, gain new experience, they are motivated, and (as added value) there is often a good atmosphere and fun on seminars and lectures. Using creative teaching methods and approaches are effective in moving students into learning zone. Jennifer Rinkevich (2011, p. 2019) defines creative teaching as a ,unique, customized, and meaningful exchange of knowledge among all individuals in a learning context" and more creative way of teaching subjects diminish students' dislike for them. Mayer (as cited in Cardoso de Sousa 2011, p. 9-10) defines creative teaching as follows: "creative teaching refers to instructional techniques that are intended to help the students learn new material in ways that will enable them to transfer what they learned to new problems." Morris (2006, p. 4-5) in the context of creative teaching points out that "creative teaching may be defined in two ways: firstly, teaching creatively and secondly, teaching for creativity" and adds that "teaching for creativity must involve creative teaching. Teachers cannot develop the creative abilities of their students if their own creative abilities are undiscovered or suppressed." Similarly, Cardoso de Sousa (2011) emphasizes the necessity of the distinction between the creative person who happens to be a teacher, and the act of teaching in a creative way.As notes Cimermanova (2013) the students' creativity depends on creativity of teacher, on how creative task is and mainly how much creativity does the teacher allows and/or accepts. One of the problems (barriers) of the more intensive use of creativity in education (as well as teaching) is the unwillingness of teachers/lecturers accept the students' creativity. In this regard, Plucker et al. (2011) point out that ideal student in the eyes of many teachers does not have creative characteristics, many teachers prefer and appreciate students' qualities such as consistency in doing tasks/work on time, courteousness or good nature (characteristics that are not very typical for creative people). University graduates - future employees and eventually managers of enterprises and firms are expected to have creative abilities which they can exploit in the working life and therefore cause change in the work environment (Ng'ang'a \& Otii, 2013). Kerr and Lloyd (2008, p. 487) argue that creative capabilities (imagination, inventiveness, improvisation, insight, intuition, and curiosity) are sought after by business for long-term success. Authors suggest that "management education must follow suit in providing artful learning experiences to assist with developing creative habits". These aspects should necessarily reflect in the education of future managers - they should be able to "manage" the creativity of employees, and they themselves must be creative and innovative and thus prepared for sudden changes in the business environment and within the organization (Ali Taha et al., 2014). Based on the assumption that everybody has creative capacities and potential, we believe that the use of "right" techniques (brainstorming, role-playing, mind mapping, fishbone etc.) and teaching procedures can foster and develop students' creativity. Although creativity and ability to think "outside the box" is becoming critical to the success of students (future managers) in the labour market, 
"traditional" (teacher-centred and passive-receptive) pedagogical approaches still dominate and in the existing structure of the curriculum there is a lack of courses supporting or "giving enough space" for creativity. We can conclude that into the curriculum as part of the teaching and development of students' creativity was the right step. Unlike the majority of courses with predominant "traditional" and "passive" learning methods course is seen as interesting for students and valuable in developing their creativity. Most of the students in the survey claim that course was something "new" and interesting for them and these opinions during the four academic years did not substantially differ. In discussions with students is evident that many of them would like to see more interactive, experiential and creative forms/methods of teaching and more interactivity in the learning process. Likewise authors' experiences in teaching other courses (Cross-cultural Management, International Management and Risk and Crisis Management) show that active learning pedagogy is the right choice. We are inclined to the view of Robyn Gibson (2010) that by fostering creativity in our students, we ultimately become more creative teachers(12)

The world is currently struggling with a serious financial and economic crisis. Until recently, it was the support of a knowledge-based economy that has been viewed as an efficient tool in the fight against the crisis. However, there is an increasing belief that the crisis cannot be overwhelmed without the support of the so-called creative economic. Indonesia currently struggling with the financial and economic crisis. One way to get out of the crisis is to stimulate economic growth, for example by supporting the so-called creative economy, which includes all areas of human activity based on original creativity and the value resulting from it. Creative industry, forming the core of the creative economy, consists of industries which have their origin in individual creativity, skills and talent and which have the potential for creating wealth and employment opportunities. Slovakia has great potential for the development of the creative economy, which derives from its cultural, social and geographical context. The aim of this paper is to support the creative industries through education reform. Creative industry in mutual synergy with a knowledge-based economy creates conditions for a strong and sustainable creative economy. It is necessary to remove barriers in science and research, to ensure appropriate protection of intellectual property and to lead towards creativity. Thus, we would like to introduce creative industries into practice through innovative university study programmes designed on the principle of interdisciplinarity and interconnectivity with practice.(9)

The Knowledge-based Economy in the 20th century society started to realise its importance, and it has since become an integral part of economic theories and models. The economies of all developed countries are currently based on knowledge and information, and therefore they are referred to as knowledge economies. Their functioning is conditional upon creation, distribution and use of knowledge and related information. Information and knowledge are considered to be the primary and the most productive source of wealth creation (P. F. Drucker, 1993) and have therefore replaced traditional sources used in the recent past, such as capital and energy, or earlier ones like land and labour. The transformation of economies into knowledge-based economies is connected with the emergence of the post-industrial society. In his work PostCapitalist Society (1993). The creative economy, in synergy with a knowledge-based economy, is able to transform towns and regions into economically more active and attractive places for life. We strongly believe that educational institutions should become key partners of local and regional governments in the development and maintenance of creative potential in towns and regions. We hope our draft of innovative and interdisciplinary study programmes will contribute, after their implementation, to the enrichment of the current offer of study programmes in the Banská Bystrica region, attract more talented and creativity-oriented young people to the region and ultimately create the preconditions for the establishment of vital businesses operating in some of the creative industries, thereby enlivening the spectrum of the business sector in this region(13).

\section{RESEARCH METHOD}

This study is exploratory-qualitative, are exploring or digging potential, positive and negative impacts, as well as the possibility of redesign, reorientation and renewal of indonesia economy education curriculum paradigm based on creative economy, character education and local cultural values. In the end, based on the data and information potential, the positive and negative impacts of economic curriculum development, and then analyzed the decision of whether to allow the as a comparison. This research is an exploratory-qualitative, so in this study did not talking about the population and size of the sample, as this study does not intend to make generalizations to the population. Qualitative data collected through in-depth interviews and group discussions are generally sourced from primary sources that respondents or informants. Kind, among other things, opinions or views the importance of redesign, reorientation and renewal of indonesia economy education curriculum paradigm based on creative economy, character education and local cultural values. Types of data and information that is quantitative or numerical data in the form of numbers, the more comes from secondary sources, from Curriculum Document. This research data is sourced from secondary sources and primary sources. Source Secondary data is data sourced from both parties. Data derived from secondary sources complement the data obtained from primary sources. Given this type of research is exploratory-qualitative data collection studies using several methods, namely: Observation is a method of data collection by making observations (observation) or a look-see, which in this observational study conducted at a location that developed into a tourist town. Data analysis techniques used in this research is descriptive qualitative, that gives interpretations, meanings and in-depth discussion of the facts and qualitative information collected, so as to depict or describe the phenomenon of research and answer the research objectives.

\section{RESUlT AND DisCUSSION}

A significant problem in Indonesian education is the fact that standards of achievement have been too low and, more importantly, too narrow. An education system that 
concentrates only on particular types of intelligence undervalues the student's natural capacities and potential when in fact these resources really are rich and various. Humans perceive the world in diverse manner of the senses. It shows the diversity of human intelligences and various modes in which humans think and communicates. Current education tends to emphasize on verbal and mathematical mode of thought. Utilizing words and numbers are considered as the supreme triumph of human intelligence. Of course, these skills are important to the intellectual growth of students, but they do not reflect the whole of education. If education were limited to these two qualities, human experience would be inexpressible and most of culture would not have appeared.

Schools are no longer the only provider of education. All members of a society display interest in the quality of education and many other parties are able to contribute from different fields of expertise. Partnerships between schools and its stakeholders become an important part of educational development. Partnerships with external organizations and individuals will enhance and broaden the experiences of students and will support teaching and learning. Bringing a design-oriented perspective to creativity, involve that actions, objects as well as events must be understood in the context of the situation of which they are part. In this regard, Dewey (1966) emphasises the notion of inquiry, acknowledged as a mode of action. This resonates with Beardon, Ehn \& Malmborg (2002, p. 503) who argue that creativity constitutes a mode of interaction with the world rather than being a property of a person, process, product, or environment. According to Kress (2010) interacting with the world includes engaging in multimodal design as a sign-making activity. Yet, while being an inherently knowledge-based process, creativity from this perspective is more than mere information processing but a direct involvement with the world aimed at its transformation. As students increasingly engage in multimodal design (sign-making), this perspective has substantial implications for the classroom habitus (Bordieu, 1986). Conceptualising economic creativity as a designoriented practice entails, among others, the following propositions:

- Creativity and learning is mediated by artefacts and results in a transformation of the physical world. Artefacts provide essential resources for agents to communicate, store, catalyse, evaluate and reflect on ideas while trying to overcome the indeterminate situation. Artefacts, from this perspective, are not mere carriers of information, but enable and constrain an actor's moves (cf. Kress, 2010; Biskjaer \& Dalsgaard, 2012).

- Creativity and learning goes along with the generation of new knowledge. As creative practices attempt to act upon a hitherto indetermined situation, the outcomes of this attempt necessarily add to the actors' body of knowledge either in that assumptions about the situation are contested or supported. Creative practice hence can be understood as a form of inquiry (cf. Dewey, 1966; Schön, 1992; Kress \& van Leeuwen, 1996; Kress, 2010).(14)
Economic Curriculum design guidelines identified themes and economic challenges in facilitating well-considered use of technology as well as meaningful ways to utilize these technologies in learning marketable situations, supply and demand. Building on this, the next step would be to establish the requirements, which includes an expansion of the initial conceptual models and an inclusive process of 'getting concrete', i.e. to put the sketches and guidelines in to action. For example, to concretise and explore in more detail which technologies that can be used for what actions, which functions the different technologies should perform and which the students and teachers would perform, how the functions are related to each other and what information needs to be available in order to resonate with the design guidelines, the pedagogical practice and the economic curriculum. The aim of such a requirements economic activity is (i) to further concretise the design guidelines, their activities in relation to the every-day practice of teaching and learning within secondary education institutions as well as to the curriculum, and accordingly (ii) to produce a set of requirements that can form a solid basis for the actual secondary school environment and which could be directly implemented, both technically and pedagogically. Thus, the focus would be on different kinds of requirements; technical and pedagogical, which might include requirements such as learning goals (for a specific economic education subject), design of economic learning environments/situations, functional, data, context of use, student (and teacher) characteristics, and usability goals. Information and communication technologies are cultural resources. They are taken up to their full potential or not; inserted or not into educational practices by teachers and students according to actual or felt social and/or pedagogical requirements and constraints (cf. Kress, 2010). Inspired by Kress (2010, pp. 196-197) and based on the design guidelines, outline some essential aspects about the desirability of skills for young people and which, hopefully, appeal to a startingpoint for discussion regarding well-considered use of technology as well as meaningful ways to utilize these technologies in learning situations, including the schools' responsibility to engage with these aspects in a reflective way: - The ability and skill to act flexibly in communication and learning with a disposition to adaptability. - To understand principles of learning as the effect of sustained engagement by a student with aspects of a learning environment. - To have the skills and required disposition towards production through the use of information technology. In this way, schools would need to provide "navigational aids" which enable students to be reflective in their use of skills, for example when it comes to awareness in selection. Furthermore, schools would need to be aware of and prepared to take the initiative to fill gaps of what is not afforded, for example: - Reflection on the use of information technology in relation to aims, purposes and designs. - The ability to engage in self-reflection. • Fostering a disposition towards agency which values representation as content creation. - Encouraging fully "involved" attitudes to the students' life-world. - Encouraging the foregrounding of strategic dispositions: a disposition towards "architecture" and "building" rather than one of mere navigation and selection among given options(2) promote creative skills development in children and young people' (LTS, 2011). In this context, 
'learning environment' was taken to extend beyond the physical architecture of the space in which learning takes place (Dudek, 2000) to encompass psychosocial and pedagogical features (Fraser \& Fisher, 1982; Roth, 2000); and should include the influence of places and people outside the school. Similarly, the phrase 'creative skills' was to be interpreted broadly within the review, par- ticularly since it is not well-represented in the literature. Thus, creative thought processes (Mumford, Mobley, Uhlman, Reiter-Palmon, \& Doares, 1991), creative problem-solving skills (Williamson, 2011), creative thinking (Torrance, 1977), cre- ative learning (Jeffrey, 2006) and possibility thinking (Craft, 2000) could all fall under the general heading of 'creative skills', acknowledging that such skills have both cognitive and practical elements. This is not the first literature review of creativity in education; for example Loveless (2002, 2007) undertook a literature review in creativity, new technologies and learning, whilst Banaji and Burn (2006) and Banaji, Burn, and Buckingham (2010). have reviewed a range of literature from which nine 'rhetorics' of creativity emerged: creative genius; democratic and political creativity; ubiquitous creativity; creativity for social good; creativity as economic imperative; play and creativity; creativity and cognition; the creative affordances of technology; and the creative classroom. In Scotland, Curriculum for Excellence (2004) is built around four capacities, one of which - successful learners - includes the encouragement to 'think creatively and independently'. The publication of a revised Action Plan for Education and the Arts, Culture and Creativity demonstrates strong Scottish Government support to '. develop a shared vision for creativity and its role in learning and teaching in the context of Curriculum for Excellence, highlighting the importance of the creative skills of children and young people, and the characteristics which should be promoted by creative learning and teaching in the arts and culture, and across the curriculum' (Scottish Parliament, 2010, p. 6). A survey of evidence from inspections of pre-school centres, primary and secondary schools and community learning and development (CLD) recommended a synthesis of elements of good practice in promoting creativity. In England (2010), identified a similar set of characteristics of effective creative teaching(5).

The review highlighted several key characteristics of the environments and conditions that are most effective in promoting creative skills in children and young people. These include the physical environment, availability of resources/materials, use of the outdoor environment, pedagogical environment, use of other environments beyond the school, play based learn- ing, effective and flexible use of time, and relationships between teachers and learners. The common features seen to be promoting creativity were flexibility in the physical and pedagogical environment, learners having control of their learning and ownership of the activity, varied physical environment at school and elsewhere such as museums, flexible use of time (including time beyond school and curriculum boundaries), and allowing pupils to work at their own pace without pressure. An important feature of the pedagogic environment that can promote creativity is the nature of the relationship between teachers and learners, including high expectations, mutual respect, modelling of creative attitudes, flexibility and dialogue. There is strong evidence that pupil creativity is closely related to opportunities for working collaboratively with their peers, which can productively extend to peer and self-assessment. There is evidence that suggests an impact of creative learning environments on learners' academic achievement; increased confidence and resilience; enhanced motivation and engagement; development of social, emotional and thinking skills; and improved school attendance. The evidence from the review suggests that teacher skills and attitudes; a willingness to act as a role model; awareness of learners' needs; flexible approaches to curriculum and lesson structure; particular types of classroom interaction with pupils, together with the use of ICT and assessment, are important components of teaching for creativity. The evidence also highlights the importance of school culture in supporting or impeding creative practice; the need to elicit teachers' prior conceptions of creativity in education; teachers taking on the role of learners to develop their own creativity; working co-constructively with a mentor or coach - which may be a creative professional from an outside agency; and the importance of teachers undertaking action research and reflection on their own classroom practice. in developing creative learning environments for children and young people are as follows:

- Present to schools the evidence of impact on pupil attainment and attitudes of creative learning environments outlined above.

- Clearly distinguish between the roles of 'critical events' (projects, themed weeks, work with outside agencies) and on- going good classroom practice in the establishment of creative environments, since there is evidence from the review that much 'creative' work in schools is associated with special initiatives which do not necessarily influence ongoing practice - therefore there needs to be an emphasis upon everyday classroom creative environments.

- Provide guidance to schools on the establishment and maintenance of partnerships with arts and other community organisations to enhance the creative environment and facilitate CPD, so that such partnerships have a long-term impact on pedagogy.

- Provide support to teachers to focus upon the processes of creative skills development rather than outcomes, as review evidence suggests that external pressures in terms of achievement or exhibition deadlines can tend to distort creative relationships in the classroom and hence disturb creative learning environments.

- Issue guidance to teachers on the flexible use of physical environments - including the outdoor environment, time and planning to best support children and young people's creativity.

- Raise teachers' awareness of the importance of positive respectful relationships with the learners whereby they model creative attitudes, are flexible and encourage dialogue. 
- Teachers should provide pupils more control of their learning and opportunities to work at their own pace and with peers.

- Commission CPD for teachers that elicits their preconceptions of creativity; stimulates dialogue around models of creativity, teaching and learning; provides them with opportunities to develop their own creativity and engages them in reflective professional enquiry into their own pedagogy.

- Future research in this area needs to be methodologically sound and transparent which can provide clear evidence of the effectiveness of creative learning environments.

- It is important to undertake research which explores the links between the effectiveness of creative approaches and diversity of the learners including ethnicity, socioeconomic status, etc.

- Further research is required that can clearly establish the impact of creative learning environments on pupils' attainment, motivation, and emotional and social skills. Research designs that capture the baseline prior to the introduction of creative curriculum or environment might help in establishing this evidence clearly.

- It is important to undertake participatory studies that capture the voices of learners and gives them ownership of the research process in line with the key characteristics of a creative environment.

- Cross-sectional and longitudinal studies should be undertaken that can identify the impact across school years and ages as well as the short and long term impact of creative environments in schools.

- It is important to undertake further studies that explore the impact of the organisational culture and supportive environ- ment on teachers' willingness and readiness to undertake and sustain creative activities in schools.

- Research needs to be conducted to identify the best ways of building up on one-off critical creative events so that they can be embedded into the day to day curriculum of the schools.

- A wider international literature review should be undertaken that takes cognisance of empirical studies, including those with more experimental research designs. It might be useful to undertake this as an international collaborative project so that the researchers can present their unique insights about the systems in their own countries but also a unique perspective on those in other countries. Further research is required to identify the link between curricular areas and creativity, with a view to identifying the best ways of embedding creativity in a cross-curricular context(9)

Professional education provides not only the development and improvement of professional competence, but also an increase of the general cultural level. It is the harmony of the overall cultural, socially moral and professional development that promotes creative formation of a human being in his life. General cultural competence can be attributed to inter-subject and / or above subject. Among these environmental competences as components of ecological culture of personality are the most popular due to the necessity of "sustainable development" of society, and implementation of professional occupation, taking into account environmental safety. Therefore, the development of ecological culture during the process of learning in higher education system, involving a display of ecological competence in a subsequent career, is relevant. Ecological culture is seen as the highest expression of human environmental education and environmental competence (Ignatov, 2011). It contributes to the formation of a true human of intelligence and civility. Furthermore, the development of ecological culture of the person acquires the status of public education standard. There is a view according to which education is seen as a necessary condition for the creation and maintenance of a constructive dialogue on environmental improvements (Beyersdorf, Michelsen, \& Siebert, 1998).

The literature discusses the impact of education on the environmental setting and views of students and adults. The results of these studies often show that in general there is a positive correlation between level of education and personal environmental awareness (Huber, 2001, P.234). Therefore, education is a factor that positively affects the environmental settings: the higher the educational level, the more clear individual guidelines on the protection of the nature (Grunenberg \& Kuckartz, 2003, P.54) and higher environmental consciousness (Kuckartz \& Rheingans-Heintze, 2006, P.52). However, comparative characteristics of ecological competence and ecological culture of students enrolled in different educational programs, is still poorly understood. We can assume that there is a relationship between the selected educational program and environmental competencies of students, the future graduates, as appropriate training modules of educational programs filled with unequal teaching material, which affects the acquired knowledge, promotes understanding of environmental problems, making judgments and basic everyday behavior of students. Assuming that environmental culture is an integral category that embraces many components, among which most often mentioned are cognitive, emotional- aesthetic, value-semantic and active (Glazachev \& Kozlova, 1997), we have identified indicators and criteria that can be used to define high level of environmental culture development of the students: The presence of environmental interests, fundamental ecological knowledge and understanding, as well as interaction skills with natural objects Maturity of the system of beliefs and values that characterize the attitude of the individual to nature. Update of the environmental relevance of teaching and research work, Carrying out the research on environmental issues, The constant need to communicate with nature and responsibility for the results of interaction with it.(15) It is necessary to develop learning activities by means of information technology so that the learners will have creative thinking skills. So, the author is interested in developing a model of Collaborative Learning through electronic media with Creative Problem-Solving Process in a U-learning 
environment to let the learners enhance their creative thinking skills. A conceptual framework of a teaching model will be synthesized, and the suitability of learning activity by experts will be examined. The objective, therefore, is to obtain a conceptual framework of this learning model, which can actually be applied efficiently.(8) Discussion education is not only determined by the effort of the individual student, but also the effort given by the teachers in managing education in schools. This is how the education design is important to prepare or to facilitate the teachers in performing their duties. With the help of a properly planned education design, the teachers can organize and manage the learning process according to the abilities, talents, interests and psychological condition of the student. The education design is important to support the effective transfer of knowledge between teachers and students and the nurturing of a learning culture. The process contains the understanding of the students, formulating learning goals, and planning a treatment using various mediums to help the learning process. Learning how to learn is one of the most important elements in education. The following discussion highlights three important values to have in order for a more proper planning of education design in schools. To improve the education design, an increasing and widening participation of students need to be encouraged in the new emphasis on learning and on defining the threshold standards for achievement. The system requires an understanding of the local and regional potential of education, which emphasize the importance of more effective staff policies and practices within the framework of a strong relationship between the Government, students, employers and institutions. The need to address issues to improve the quality of education led to reviews of the education design and structures. This need to be balanced with the belief that education is not just about creating workers, but also about developing people. The education system needs to works in the Indonesian context, not just for now but also for the years ahead. The education design being put forward in the following section will address technical teaching and classroom management, as well as the way teachers can better deliver the curriculum.

A balanced education system necessitates a broad range of opportunities for students to discover and grow in different aspects of intelligences with a stimulating approach to teaching and learning. Talent manifests in many forms and should not be labeled merely by conventional academic measures. An essential function of teachers is to recognize, identify, and acknowledge students' potentials and to make available the conditions in which these potentials can be nurtured. With proper support, self-confidence and self-esteem will grow and overall performance improves, leading to the discovery of the student's talent. Accordingly the teachers should possess more liberty to draw on their own creative and professional abilities to do this. Greater flexibility in the classroom will encourage creative teaching. Furthermore, the teachers need to be properly trained. This is important to support creative learning as the greatest constraints to success are low self-esteem and lack of motivation.

Creative ecomic and cultural education is not merely subjects in the curriculum, nor that it is a supplement that should be added to the work of schools. Instead they are universal values in education. They correspond to an essential factor in increasing standards and improving the effectiveness and quality of education throughout the curriculum. Creativity, similar to learning, is a very much a personal process. Each individual has different talents and different manners in understanding ideas and interpreting facts. It is important for the education system to accommodate these differences and avoid a single standard method for everyone to conform at the same time in the same way. On the other hand, although creative work entails an expertise of certain required skills, focusing on skills alone may impede interest in any subject. For example, a lot of people despised learning math because they are forced to do tasks that did not stimulate their interest. Second, teaching for creativity. This is the type of teaching that are designed to build a student's creative behavior, which include encouraging (to assist student to trust their creative potential, to distinguish their sense of possibility, and to give the willingness to try), identifying (facilitate student to discover their own creative power), and fostering (recognizing and familiarizing the creative process in stimulating creative development). Determining the quality of a learning model must be viewed from two aspects, namely processes and products. The processes aspect refers to whether the learning process is able to create a situation of learning and creative thinking. The product aspect refers to whether the learning process is able to achieve the objectives, namely to increase the ability of students according to pre-specified criteria. Improving creative and cultural education would address systemic issues that affect all elements of the education system, including methods of teaching and assessment, the role of schools and other general aspects of educational management. The core of education is the relationship between teachers and students, as well as the relationships between fellow students. A big issue is that newly qualified teachers have insufficient training in these areas. This happens because they are confronted with a complicated practice of performing for the existing standards, teaching a curriculum consisting of core subjects, and preparing students for school experience in more than half of the course time available. They teach knowledge to pass exams, rather than building a learning culture. Another important consideration is cooperation of the teachers in a school. This is particularly vital in making learning strategies starting from the syllabus, lesson plans, and the form of assessment. If this can be done accurately then the learning can also enhance the cooperation. In addition to improving collaboration, it also increases the urgency for teachers to update and broaden their own knowledge continuously.

According to Samani (2002), in general there are two approaches in the preparation of a curriculum, which is subject-matter based and competency-based. In the subject matter approach, the curriculum is prepared based on conventional study subjects. Therefore the subjects are very similar to the field of science and the content of learning is very similar to the theories or concepts that exist in the respective subjects. This model employs the assumption that if a person has mastered the theory or concept according to its appropriate level, then they will automatically be able to apply those theories or concepts in real life. Thus, the main objective 
in this model is mastery, whereas the application of the science itself is secondary. Competence based curriculum are oriented on two aspects, First, the impact and the expected results of a learner are attained through a series of meaningful learning experiences. Second, the diversity should be manifested in accordance with what is expected to be learnt, addressed, or illustrated in a gradual and continuous progress to be competent. In the competency-based approach, the curriculum is directed so that students are able to master certain competencies in accordance with the line of future profession or areas of expertise, with a variety of other attributes in its development. In this model, knowledge is not only the framework but also a source of competency. This means that to master the targeted competencies, students need to equip themselves with the necessary theories and concepts. In this way, there is a possibility that there is a limited quantity of concepts or theories that are included in the curriculum, as the remaining is deemed unnecessary. The major concern in the competency-based approach is the required competences of the graduates in order to be able to successfully pursue a profession or expertise and the learning of knowledge are done according to needs.

Creative abilities, which are an important point in this matter, are built by practical work with the habit of engaging in the practice of creative thinking production. There are particular methods and skills that are specific to different fields and types of work, but there are also various common qualities of creative processes, which can be experienced and understood. The Wallas model (1926) was ground-breaking in its concept of introducing the sub- conscious into the ideaforming process. This model triggers other creative thinking processes. In applying creativity in education, it is helpful to understand the framework which introduced the classical classification of steps in creative thinking, namely, preparation (furnishing an idea with a preliminary form or outline), incubation (withdrawal from thinking about the idea and utilizing unconscious mental processes), illumination (shaping and clarifying the idea in the route of exploring and perfecting details), then verification (critical appraisal to assess logic and relate idea to evidence, practicability, utility and audience response). In this framework, two modes of thought can be identified which is generative and evaluative. Imaginative activity is a generative mode of thought, whereas creativity involves both generative and evaluative modes of thought. At the right time and manner, thorough critical assessment using evaluative mode of thought is necessary. However, at the wrong situation, it can kill an emerging idea. The balance between these modes of thought must be right in incorporating creativity within the design of education.

Creative thinkers are important not only to answer today's problems, but also to discover new problems that people had not thought of. Further opportunities should be provided to young people to identify problems for themselves, in addition to finding answers to prearranged problems. Creative accomplishment requires knowledge, control, and discipline balanced with freedom and confident to experiment. Creative thought often takes place when novel connections are created between ideas or experiences that were not linked before. These take place across and within various fields.
Freedom to experiment is crucial for creativity, but skills and knowledge of the fields also plays an important role, as knowledge of the field is required to understand the media and materials involved. Integrated learning as a concept can be considered as a learning approach that involves several areas of study to provide a meaningful experience for the students. It is meaningful because of the integrated teaching approach, where children understand concepts through direct observation and relating it to other concepts previously acquired. In the integrated learning approach, exploration is central to curriculum development. Students are then expected to gain hands-on experience that enable acceptance, storage, and application of the concepts learned. Thus, students are trained to be able to find themselves studying concepts that become meaningful, authentic, and active. The way teachers design their learning experience is very influential not only on how meaningful it is for students, but also how effective the process can be. Learning experiences that involve relationships between various conceptual elements will enhance the effectiveness of the learning process. Adaptation to the environment is done through a process of assimilation and accommodation. According to Slavin (1994) assimilation is the process of interpreting new experiences in relation to possessed patterns of behavior or thinking. Learning depends on the balance between understanding the process of recovery from the clash between new experiences and possessed knowledge. When balance takes place, the person has the opportunity to grow and develop. The teachers can take advantage by creating situations that are intended to disturb the balance, therefore inducing curiosity in students. The importance of environments in a learning process is put forward by Jean Piaget (Wood et al., 2001), who believes that social interaction with peers, particularly in argumentation, helps clarify the thinking process, and ultimately making it more logical. This development depends in part on how far a person actively manipulates and interacts with the environment. This indicates that the learning environment will determine the cognitive development of a person. However, there are some implications of Piaget's theory of learning such as the fact that education should focus on the child's thinking process apart from the result For example, as well as checking students' answers in a test, the teacher must also try to understand the process of arriving at the given answer. Introduction and recognition of the role of children is important in achieving initiative and active involvement within learning activities. Education should also accept individual differences in the developmental progress because although children grow through the same developmental sequences, they do it at their own pace. Thus the teacher should give priority to students in their initiative and active involvement in learning activities. Also, the teacher should avoid spoon-feeding knowledge, and should aim to nurture students to find knowledge through interaction with the environment(16).

The partnership concept is composed of different representatives of key actors in the fields of entrepreneurship and vocational education: organisations which deal with vocational learning, adult learning and advisory activities for enterprises; associations of enterprises which play an active role in the definition of policies and politics, and keeps strong 
relations with institutional bodies such as Government, Parliament, parliamentary and non-parliamentary committees and political parties; - organisations which work for the development of creativity skills and competences. The presence of these partners will be important in order to plan and develop tool, methodologies and approaches. The analysis highlights that creativity education is often addressed to pupils, youth, unemployed people which participate in entrepreneurship training programme. Creativity is considered, in fact, a general entrepreneurial ability. There is not, however, a systematic approach for the development of creative skills in continuous training. The decision to invest or not in the development of the creative skills of the staff of the enterprises depends on the owners or managers of each company; - the development of a context analysis about the previous educational experiences realised in the field of creativity, carried out at local and regional level by some partner. The results highlight that there is not a systematic approach for the development of creative skills in continuous training; In relation to the start of art within the field of operation, the main innovating elements are: - the focus on creative skills, as the main instrument to develop vocational and entrepreneurial competences and innovation; - the construction and testing of an index for measuring the creativity of enterprises within the reference areas of the project, in order to define the economic and socio-cultural contextual factors that facilitate or hinder the development of creative skills; the development of a participatory path to plan and realise, workshops of business theatre aimed at facilitating the expression, the expansion and the enhancement of creative thinking in business and to produce innovation through the exchange of creative and entrepreneurial skills among old and new generations of entrepreneurs and managers; - the promotion of consultation processes among entrepreneurs, managers, professional associations, policy makers, adult training centres, aimed at encouraging the introduction of creative skills in training plans. - supporting improvements in quality and innovation in vocational education; - fostering the integration of learning with working life, promoting more learning conducive environments at the workplace, workplaced training and apprenticeship pathways as a basis for the development of vocational skills relevant to the labour market needs; - developing creative skills among entrepreneurs and managers to improve new innovation-driven role models and management approaches; - creating within enterprises an environment and a climate which lead to development and innovation; - promoting and developing the exchange of expertise among the different generations of adults which work in enterprises; - contributing to facilitate processes of repositioning and/or overcoming the economic crisis for enterprises; - promoting new networking between enterprises and adult learning organisation in order to promote creative development and innovation; developing new analytical and training tools, new methodologies, new approaches which promote and encourage the introduction of creative skills in corporate training plans. - setting up and testing of an index for measuring the creativity of enterprises in order to define the economic and socio-cultural contextual factors that facilitate or hinder the development of creative skills; defining competences and skills necessary for entrepreneurs and managers to identify, develop and enhance their own creative skills and those of their employees, and to foster creativity among their staff; - realising experimental training courses for entrepreneurs and managers within the reference areas of the project to allow the acquisition of competences and skills previously defined; - developing a participatory path to plan and realise workshops of business theatre aimed at facilitating the expression, the expansion and the enhancement of creative thinking in business and to produce innovation, also through the exchange of creative and entrepreneurial skills among old and new generations of entrepreneurs, managers and enterprise workers; - elaboration of a Creativity Handbook for Entrepreneurs and Managers, by collecting and processing didactic and multimedia materials realised in experimental training course ; - promoting and developing a networking action to promote creativity and innovation in working approaches, entrepreneurial role models and processes through the exchange of experience between them and the organisations which work in order to develop creativity in workplaces; - elaboration of a Memorandum of Understanding among enterprises, professional associations, policy makers, adult training centres aimed at ensuring the sustainability of the project. With relation to the specific objectives stated, the expected results are: - identification and measurement of the contextual factors which facilitate or hinder the creativity of enterprises within the reference areas, in order to provide qualitative and quantitative data for setting educational and development policies/strategies for enterprises; - production of an innovative curriculum necessary for entrepreneurs and managers to identify, develop and enhance their own creative skills and those of their employees, and to foster creativity among their staff realisation of experimental training courses, to train entrepreneurs and managers; - acquisition by entrepreneurs, managers and enterprises staff of skills and competences to facilitate the expression, the expansion and the enhancement of creative thinking in business, through the methodology of the business theatre; - planning and testing new methodologies for the exchange of creative and entrepreneurial skills among old and new generations of entrepreneurs, managers and enterprise workers; - setting up of network between enterprises, and between them and organisations which work for the development of creativity in workplaces, to promote and develop creativity and innovation in working approaches, entrepreneurial role models and processes; - implementation of actions to encourage the introduction of creative skills in corporate training plans through a process of consultation among enterprises, professional associations, policy makers, adult training centres(17).

It needs collaboration among other parties (triple helix theory) such as education institution, government, and entrepreneurs to develop and improve entrepreneurship in Indonesia. Each party has their own role. In education institution, learn from the experiences, entrepreneurship can be taught by constructing multidiscipline curriculum. The economic curriculum should comprise of entrepreneurship theories and practice includes business knowledge and entrepreneurship skill (all material related to creativity, innovation, new venture creation, and venture financing). Entrepreneurship programme should be differentiated from 
other programme in terms of learning methods, entrepreneurship programme should be conducted in lecturing, practicing, mentoring, and assistantship with academicians as well as entrepreneurs. The role of entrepreneurs can be applied in the form of the business incubator. Presently, business incubator still has to be improved in order to develop entrepreneurship in Indonesia. The role of business incubation can significantly help improvement in product quality of business and management skill of new entrepreneurs.(18)

The creative economy, in synergy with a knowledgebased economy, is able to transform towns and regions into economically more active and attractive places for life. We strongly believe that educational institutions should become key partners of local and regional governments in the development and maintenance of creative potential in towns and regions. We hope our draft of innovative and interdisciplinary study programmes will contribute, after their implementation, to the enrichment of the current offer of study programmes, attract more talented and creativity-oriented young people to the region and ultimately create the preconditions for the establishment of vital businesses operating in some of the creative industries, thereby enlivening the spectrum of the business sector in this region. The potential of cultural and creative industries the term "creative industry" is perceived in connection with the socalled "cultural industry". It is characterised by "a dual nature, being economic in that they contribute to economic development through employment, economic growth and wealth creation, but also cultural, thanks to activities integrating individuals socially and culturally into society as well as by being involved in promoting values and cultural identities and developing a cultural heritage"(10).

NCREL and Metiri Group (2003) have identified the enGauge 21 st century skills which need to be acquired by future generation in order to meet the challenges of globalization due to the advancement of information and technology. There are four main domains specified in the 21 st century skills namely digital age literacy, inventive thinking, effective communication and high productivity. The digitalage literacy skills in accordance NCREL (2003) consist of :

- Basic literacy means language proficiency (in English) and numeracy at levels necessary to function on the job and in society to achieve one's goals, and develop one's knowledge and potential in this digital age.

- Scientific literacy means knowledge and understanding of the scientific concepts and processes required for personal decision-making, participation in civic and cultural affairs, and economic productivity.

- Economic literacy means the ability to identify economic problem, alternatives, costs and benefits; analyze the incentives at work in economic situations; examine the consequences of changes in economic conditions and public policies; collect and organize economic evidence; and weigh costs against benefits (NCREL and Metiri Group, 2003).

- Technological literacy means knowledge about what technology is, how it works, what purposes it can serve, and how it can be used efficiently and effectively to achieve specific goals.

- Visual literacy means the ability to interpret, use, appreciate, and create images and video using both conventional and $21 \mathrm{st}$ century media in ways that advance thinking, decision-making, communication, and learning.

- Information literacy means the ability to evaluate information across a range of media; recognize when information is needed; locate, synthesize, and use information effectively; and accomplish these functions using technology, communication networks, and electronic resources.

- Multicultural literacy means the ability to understand and appreciate the similarities and differences in the customs, values, and beliefs of one's own culture and the cultures of others whereas global awareness means the recognition and understanding of interrelationships among international organizations, nation-states, public and private economic entities, socio-cultural groups, and individuals across the globe (NCREL and Metiri Group, 2003) .

Economic Curriculum must be adaptable and accomplish 21 st century skills comprised of four main domains namely digital age literacy, inventive thinking, effective communication and high productivity. Scientific literacy is one of the skills required in digital age literacy. It means knowledge and understanding of the scientific concepts and processes required for personal decision-making, participation in civic and cultural affairs, and economic productivity. Scientific literacy is important in our modern society since they are many issues related to science and technology. Basic science process skills include observing, classifying, measuring and using numbers, making inferences, predicting, communicating and using the relations of space and time. While the integrated science process skills consist of interpreting data, operational definition, control variables, make hypotheses and experimenting. Science students have been cultivated by scientific literacy and science process skills through science classes. With these two skills, it is hoped that the science students have developed some skills needed in $21 \mathrm{st}$ century skills. 21 st century skills, scientific literacy and science process skills. It also explains about the intersection of science process skills and 21 st century skills in science education. Inventive thinking comprises of adaptability/managing complexity, self direction, curiosity, creativity, risk taking and higher-order thinking and sound reasoning. There are consist of :

- Adaptability/managing complexity is the ability to modify one's thinking, attitude, or behaviour to be better suited to current or future environments, as well as the ability to handle multiple goals, tasks, and inputs, while understanding and adhering to constraints of time, resources, and systems (e.g., organizational, technological).

- Self-direction is the ability to set goals related to learning, plan for the achievement of those goals, 
independently manage time and effort, and independently assess the quality of learning and any products that result from the learning experience.

- Curiosity is the desire to know or a spark of interest that leads to inquiry.

- Creativity is the act of bringing something into existence that is genuinely new and original, whether personally (original only to the individual) or culturally (where the work adds significantly to a domain of culture as recognized by experts).

- Risk-taking is the willingness to make mistakes, advocate unconventional or unpopular positions, or tackle extremely challenging problems without obvious solutions, such that one's personal growth, integrity, or accomplishments are enhanced.

- Higher-order thinking and sound reasoning include the cognitive processes of analysis, comparison, inference/interpretation, evaluation, and synthesis applied to a range of academic domains and problemsolving contexts (NCREL and Metiri Group, 2003).

- Effective communication involves five components which are teaming and collaboration, interpersonal skills, personal responsibilities, social and civic responsibilities and interactive communication.

- Teaming and collaboration means cooperative interaction between two or more individuals that working together to solve problems, create novel products, or learn and master content.

- Interpersonal skills mean the ability to read and manage the emotions, motivations, and behaviours of oneself and others during social interactions or in a social-interactive context.

- Personal responsibility is depth and currency of knowledge about legal and ethical issues related to technology, combined with one's ability to apply this knowledge to achieve balance, integrity, and quality of life as a citizen, a family and community member, a learner, and a worker.

- Social and civic responsibility is the ability to manage technology and govern its use in a way that promotes public good and protects society, the environment, and democratic ideals. Interactive communication means the generation of meaning through exchanges using a range of contemporary tools, transmissions, and processes (NCREL and Metiri Group, 2003).

- High productivity consists of prioritizing, planning, and managing for results, effective use of real-world tools and ability to produce relevant, high-quality products. Prioritizing, planning, and managing for results are the ability to organize and efficiently achieve the goals of a specific project or problem.

- Effective use of real-world tools is the effective use of these tools - the hardware, software, networking, and peripheral devices used by Information Technology (IT) workers to accomplish 21 st century work. It means using these tools to communicate, collaborate, solve problems, and accomplish tasks. Ability to produce relevant, high-quality products is intellectual, informational, or material products that serve authentic purposes and occur as a result of students using realworld problems.(19)

\section{REFERENCES}

[1] Hsin-Hsi Lai, "The influence of compensation system design on employee satisfaction", African Journal of Business Management, 2011, Vol. 5(26), pp. 1071810723.

[2] Yamoah, Emmanuel, Erastus, "Relationship between Compensation and Employee Productivity", Singaporean Journal of Business Economics, And Management Studies, 2013, Vol.2, No.1.

[3] Charlesworth, Sara and Marshall, Helen,"Sacrificing Workers? The curious case of salary sacrificing in nonprofit community services in Australia" International Journal of Public Sector Management, 2011, Volume 24, No.7, pp.673-683.

[4] Setiaji, "Pengaruh Upah dan Jaminan Sosial terhadap Produktivitas Kerja Karyawan PT. Sumber Makmur Semarang”, 2009, Undip Semarang.

[5] Wekesa, Jane Nelima, Silas Nyaroo.M.A, "Effect of Compensation on Performance of Public Secondary School Teachers in Eldoret Municipality Kenya”, International Journal of Scientific and Research Publications, 2013, Volume 3, Issue 6.

[6] Useem, Michael and Andrea, "Exceptional Frontline Performance: Learning from the Medal Honor Tradition, Organizational Dynamic, 2014, 43, pp.37-43

[7] Sugiyono, "Metode Penelitian Bisnis", Erlangga, 2006, Jakarta.

[8] Singarimbun, Masri dan Effendi, Sofyan. 2006. Metodologi Penelitian Survey. LP3ES, Jakarta.

[9] Bebchuck, L.A. and J.M.Fried, "Executif compensastion as an agency problem, Journal of Economics Perspective", 2003, 17(3):71-92.

[10] Burn, N.S.K., "The impact of performance-based compensastion on misreporting", Journal of Financial Economic, 2006, 7(9):35-67

[11] Epstein, G.S., "Perceived Income, Promotion and Incentive Effect", International Journal of Manpower, 2006, Volume 27, No. 2, pp.104-125.

[12] Cushway, Barry, "Human Resource and Management, The Association for Management Educational and Development", 2004, London.

[13] Dessler, Gary, "Manajemen Sumberdaya Manusia, 2007, Prentice Hall, Indonesia. 